\title{
Fusion of a functional glutaredoxin to the radical- generating subunit of ribonucleotide reductase
}

\author{
Inna Rozman Grinberg ${ }^{1}$, Daniel Lundin ${ }^{1}$, Margareta Sahlin ${ }^{1}$, Mikael Crona ${ }^{1,2}$, Gustav \\ Berggren $^{3}$, Anders Hofer ${ }^{4}$, Britt-Marie Sjöberg ${ }^{1 *}$
}

From the ${ }^{1}$ Department of Biochemistry and Biophysics, Stockholm University, Sweden; ${ }^{2}$ Swedish Orphan Biovitrum AB, Stockholm, Sweden; ${ }^{3}$ Department of Chemistry, Uppsala University, Uppsala, Sweden; ${ }^{4}$ Department of Medical Biochemistry and Biophysics, Umeå University, Umeå, Sweden.

Running title: Glutaredoxin and ATP-cone fusions to ribonucleotide reductase

*To whom correspondence should be addressed: Britt-Marie Sjöberg, Department of Biochemistry and Biophysics, Stockholm University, SE-10691 Stockholm, Sweden; brittmarie.sjoberg@dbb.su.se; Tel +46-8-164150; Fax +46 8-155597

Keywords: allosteric regulation, ATP-cone, dATP inhibition, dimanganese, dithiol, monothiol mechanism, tetramers, radical mechanism, redox activity, ribonucleotide reductase

\section{Abstract}

Class I ribonucleotide reductase (RNR) consists of a catalytic subunit (NrdA) and a radicalgenerating subunit (NrdB) that together catalyse reduction of the four ribonucleotides to their corresponding deoxyribonucleotides. Facklamia ignava $\mathrm{NrdB}$ is an unprecedented fusion protein with N-terminal add-ons of a glutaredoxin ( $\mathrm{Gr}$ ) domain followed by an ATP-cone. Grx, which in general is encoded elsewhere in the genome than is the RNR operon, is a known physiological reductant of RNRs. Here we show that the fused Grx domain functions as an efficient reductant of the $F$. ignava class I RNR via the common dithiol mechanism and interestingly also via a monothiol mechanism, although less efficiently. A Grx that utilizes either or of these two reaction mechanisms has to our knowledge not been observed with a native substrate before. The ATP-cone, which is commonly found as an N-terminal domain of the catalytic subunit of RNRs, is an allosteric on/off switch that promotes dNDP reduction in presence of ATP and inhibits the enzyme activity in presence of dATP. Here we show that dATP bound to the ATP-cone of $F$. ignava NrdB promotes formation of tetramers that are unable to form enzymatically competent complexes with $F$. ignava NrdA. The ATP-cone binds two molecules of dATP, but only one molecule of the activating nucleotide ATP. $F$. ignava $\mathrm{NrdB}$ contains the recently identified radical factor $\mathrm{Mn}_{2}{ }^{11 / / \mathrm{V}}$. We show that $\mathrm{NrdA}$ from the firmicute $F$. ignava can form a catalytically competent $\mathrm{RNR}$ with the $\mathrm{Mn}_{2}{ }^{11 / / \mathrm{V}}$-containing $\mathrm{NrdB}$ from the flavobacterium Leeuwenhoekiella blandensis.

\section{Introduction}

Ribonucleotide reductase (RNR) is an essential enzyme that catalyze the synthesis of the DNA building blocks (dNTPs) by reduction of the four ribonucleotides. RNR plays a key role in DNA synthesis and DNA repair, and consequently attracts biomedical interest as a potential target for antibacterial substances and for anticancer therapies. Currently, the RNR enzyme family comprises three different RNR classes and several subclasses. The three classes have a common reaction mechanism that builds on radical chemistry, but differ in the way they initiate the radical mechanism (1-5). The class I RNRs consist of a larger catalytic component $(\mathrm{NrdA})$ and a smaller radical-generating metal-containing component (NrdB) 
where the dinuclear metal site differs between subclasses. Currently, class I RNRs have been subclassified based on radical cofactor type (subclasses la, Ib, Ic and Id) or evolutionary history (subclasses $\mathrm{NrdA} / \mathrm{B}$ followed by a small letter plus subclass $\mathrm{NrdE} / \mathrm{F}$ ) $(1,6)$. Metal content does not always follow phylogeny as two unrelated $\mathrm{Mn}_{2}$ subclasses exist, where one subclass contains a tyrosyl radical in the vicinity of a $\mathrm{Mn}^{\mathrm{III}} / \mathrm{Mn}^{\mathrm{III}}$ center (Ib, $\mathrm{NrdE} / \mathrm{F}$ ), and another recently identified subclass (Id, NrdAi/Bi) contains a mixed valent $\mathrm{Mn}^{\mathrm{IV}} / \mathrm{Mn}^{\text {III }}$ metal center that harbors the unpaired electron (7-9). Moreover, in eukaryotic RNRs and several evolutionarily unrelated bacterial class I subclasses, the NrdB component contains a stable tyrosyl radical in the vicinity of a diferric metal center (la). In another bacterial subclass (Ic), a mutational change in the radical-carrying tyrosine to phenylalanine is accompanied by a mixed valent $\mathrm{Mn}^{\mathrm{IV}} / \mathrm{Fe} \mathrm{I}^{\mathrm{III}}$ metal center $(10,11)$. Recently, a metal independent subclass (le) with an intrinsically modified dopa radical cofactor was discovered (12).

All class I RNRs contain a C-terminal redox-active cysteine pair in NrdA that functions as a reductant of a cysteine pair in the active site that is oxidized during catalysis. Physiological regeneration of active NrdA is performed by members of the redoxin family, with NADPH as ultimate electron source (13-15). Three types of redoxin have been found to reduce the Cterminal cysteines in class I RNRs: i) thioredoxin that receives the electrons from NADPH via thioredoxin reductase, ii) glutaredoxin (Grx) that receives the electrons from NADPH via glutathione reductase and glutathione (GSH), and iii) $\mathrm{NrdH}$-redoxin that also receives the electrons from NADPH via thioredoxin reductase even though $\mathrm{NrdH}$ is more similar to $\mathrm{Grx}$ than to thioredoxin. Whereas the $n r d A$ and $n r d B$ genes are mostly encoded by an operon in bacteria, the trx and grx genes are usually found elsewhere in the genome. Only the $n r d H$ gene is predominantly encoded by the same operon as the corresponding RNR genes, which for historical reasons in this particular subclass are called $n r d E$ (encoding the catalytic subunit) and $n r d F$ (encoding the radical-generating subunit).

We discovered an intriguing fusion of a grx gene to the the $n r d B$ gene in the bacterium Facklamia ignava, resulting in an open reading frame encoding a fusion protein. The $F$. ignava NrdB fusion protein consists of an N-terminal Grx domain followed by an ATP-cone domain and then the radical-generating subunit. An N-terminal grx fusion to the $n r d B$ gene in Francisella tularensis was noticed by us previously (16). The redoxin domain in both these fusion are most closely related to the grxC domain family (COG0695). Whereas the $\mathrm{y}$ proteobacterium Francisella tularensis is a well studied human pathogen causing tularemia (17), the Firmicutes genus Facklamia was first described in 1997 and has since been identified in samples from a wide range of animals and as a human pathogen (18-20).

RNR has been described as a textbook example of allosteric regulation in enzymes, and employs two different allosteric mechanisms to regulate the synthesis of dNTPs (21). One common mechanism regulates the balance between the four dNTPs in a sophisticated feedback control at the specificity site (s-site). An additional allosteric regulation occurs in a separate domain called the ATP-cone and works as a general on/off switch, the overall activity site (a-site). In simple terms, the enzyme is active when ATP is bound and when dATP is bound the enzyme is turned off. We have recently shown that the ATP-cone can be horizontally transferred between different RNRs and even to different subunits of the holoenzyme $(8,22)$. In an overwhelming number of cases the ATP-cone is an N-terminal domain of the catalytic subunit of RNR (22). F. ignava RNR instead carries an ATP-cone in its NrdB protein, between the $\mathrm{N}$-terminal $\mathrm{Grx}$ domain and the radical-generating domain. We have recently reported a similar N-terminal ATP-cone fusion to NrdB in Leewenhoekiella blandensis (8). Both these fusion proteins belong to the NrdBi subclass, which harbors a few additional ATP-cone::NrdB fusions.

In this study we have used the $F$. ignava RNR to study two major questions: does the fused Grx domain function as a reductant for the holoenzyme, and does the fused ATP-cone 
Glutaredoxin and ATP-cone fusions to ribonucleotide reductase

function as a general on/off switch? To investigate this, we used a series of biochemical assays to show that the Grx domain is indeed an efficient reductant of $F$. ignava RNR, and that the fused ATP-cone domain is a functional allosteric domain.

\section{Results}

\section{Glutaredoxin-fusions to RNR components}

The 496-residue F. ignava (Firmicutes) NrdB fusion protein consists of an N-terminal Grx domain (residues 4-61, with the characteristic cysteine pair at residues 12 and 15) followed by an ATP-cone domain (residues 84-169) and thereafter the NrdB proper (cf Fig. S5). The $n r d A$ gene is located 46 nucleotides downstream of the $n r d B$ gene, and the two genes conceivably form an operon (Fig. 1). The F. ignava $\mathrm{NrdB}$ is a member of the $\mathrm{NrdBi}$ phylogenetic subclass (http://rnrdb.pfitmap.org), like all other NrdBs in which we have detected N-terminal ATP-cones (8).

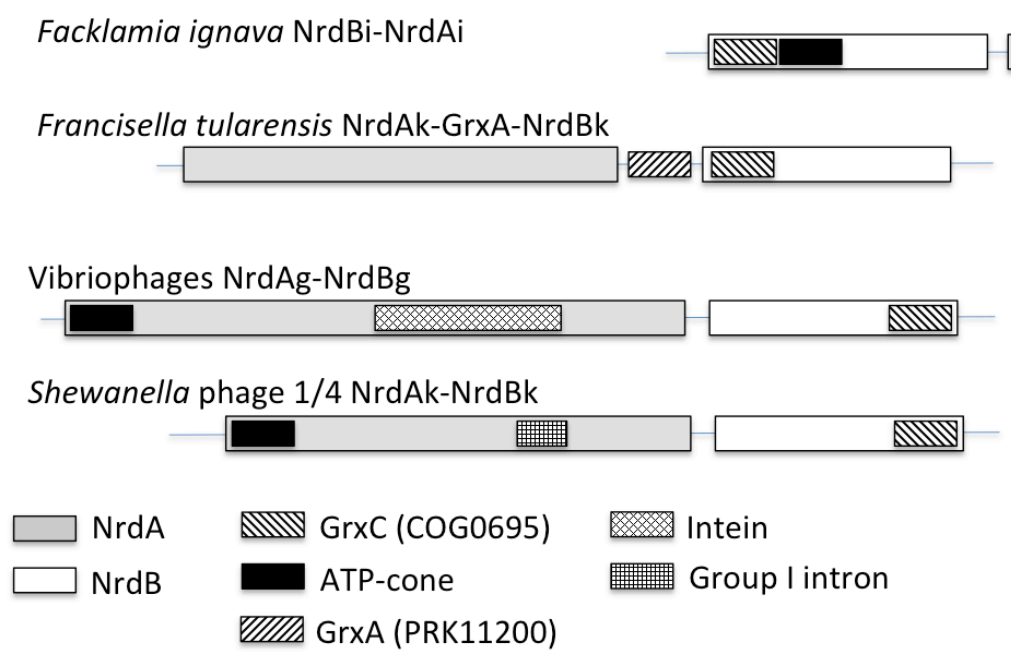

Figure 1. The F. ignava nrdAB operon and some other class I RNR operons with grx fusions. Transcriptional and translational directions are from left to right. The Francisella tularensis operon occur in all Francisella spp. and the displayed vibriophage operon is found in most vibriophages (Table S1).

Spurred by the discovery of the Grx fusion to $F$. ignava $\mathrm{NrdBi}$, we performed a search of the RefSeq database for combinations of RNR proteins and Grx domains. Grx fusions were found in all RNR components ( $\mathrm{NrdA}, \mathrm{NrdB}, \mathrm{NrdD}$ and $\mathrm{NrdJ}$ ), in some cases together with an ATP-cone (Fig. 1, Table S1). Grx fused to NrdB were detected in all Francisella spp. and Allofrancisella guangzhouensis (both Y-proteobacteria; subclass NrdBk), and in 24 viruses (NrdBe, NrdBg and NrdBk) (Fig. 1, Table S1). In addition, a grx::nrdE fusion was found in Streptococcus pneumoniae, a grx::nrdD fusion in Lachnospiraceae bacterium TWA4, a grx::nrdJ fusion in Labrenzia aggregata and grx::nrdA fusions in 2 viruses (Table S1).

As many Firmicutes lack glutathione and instead produce another low molecular weight reductant called bacillithiol (23), we also searched the $F$. ignava genome for presence of GSH biosynthesis and bacillithiol biosynthesis genes (gshA, gshB, gshF, bshA, bshB1, bshB2, bshC). F. ignava and the other Facklamia spp. but one encode the bifunctional gsh $F$ gene that is primarily found in Firmicutes (24). The Facklamia gshF has extensive similarity primarily to the gshA gene (Table S2). The glutathione reductase gene gor was only found in Facklamia sourekii. The closest ortholog in F. ignava is a mercury(II) reductase and a dihydrolipoyl dehydrogenase, both with ca $50 \%$ similarity to $F$. sourekii gor. There were no 
Glutaredoxin and ATP-cone fusions to ribonucleotide reductase

genes corresponding to the bacillithiol biosynthesis genes in any Facklamia spp., apart from a glycosyl transferase gene with some similarity to $b s h A$. Our results show that $F$. ignava and other Facklamia spp. have the capacity to synthesize GSH.

\section{Redox activity of the NrdB-fused glutaredoxin}

Using a series of cysteine-to-serine mutant proteins we have delineated the reaction mechanism of the fused Grx domain. Grx proteins usually reduce RNRs via a dithiol mechanism, but e.g. a human $\mathrm{Grx}$ has been reported to work via a glutathionylation mechanism (25-27). To test the capacity of the Grx domain in F. ignava NrdB to perform a dithiol reduction, we constructed two mutant proteins with a serine instead of cysteine in one or the other of the two redox-active residues in the Grx domain (C12S and C15S) and the corresponding double mutant (C12S/C15S).

In a first set of experiments the mutants were compared to the wild type protein in a redox cycle with the artificial substrate 2-hydroxyethyl disulfide (HED). As evident from figure 2A, the wild type and C15S mutant proteins reduced the HED substrate, whereas the C12S mutant and the double mutant did not. The $K_{m}$ for HED was $0.6 \pm 0.09 \mathrm{mM}$ for the wild type protein and $1.3 \pm 0.24 \mathrm{mM}$ for the $\mathrm{C} 15 \mathrm{~S}$ protein and the $V_{\max }$ was approximately 2-fold higher for the wild type compared to $\mathrm{C} 15 \mathrm{~S}$ at saturating HED (Fig. 2B). In a GSH titration experiment with constant HED, the $\mathrm{K}_{\mathrm{m}}$ for $\mathrm{GSH}$ was $3 \pm 0.9 \mathrm{mM}$ for the $\mathrm{C} 15 \mathrm{~S}$ mutant protein and the rate was $44 \mu \mathrm{mol} / \mathrm{min}$ (Fig. $2 \mathrm{C}$ ) corresponding to a $k_{\text {cat }}$ of $1.5 \mathrm{~s}^{-1}$. Activity in the absence of one cysteine demonstrates that the Grx domain in F. ignava NrdB can work via a monothiol mechanism utilizing Cys 12 as the redox-active cysteine in presence of HED. The behavior of the wild type protein in the GSH titration experiment (Fig. 2C) cannot be explained by a pure dithiol reaction mechanism. One possible explanation is that a monothiol mechanism may interfere at higher GSH concentrations.

A

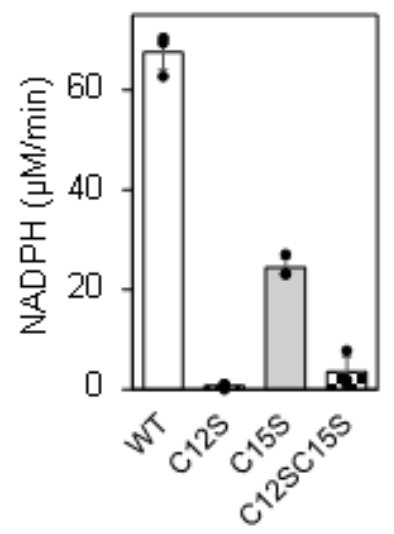

B

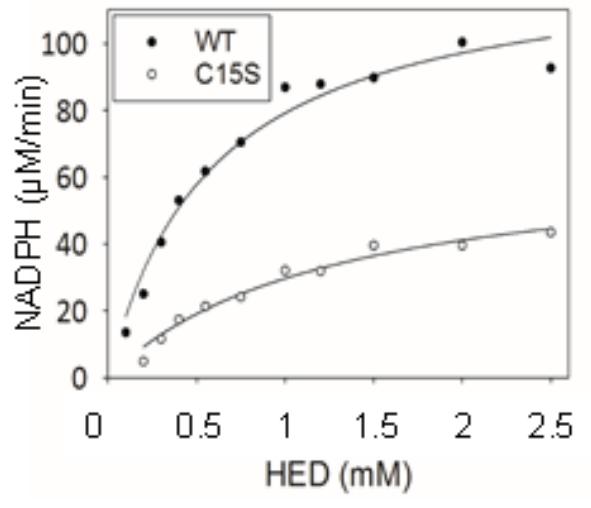

C

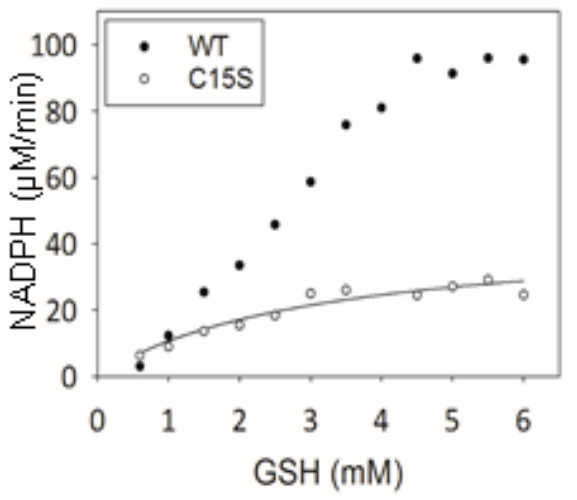

Figure 2. HED reduction capacity of $\boldsymbol{F}$. ignava NrdB. A) $0.1 \mu \mathrm{M}$ wild type and mutant proteins in the presence of $0.75 \mathrm{mM}$ HED and $4 \mathrm{mM} \mathrm{GSH}$. Assays were performed in triplicate with standard deviations shown. B) HED titration of wild type and C15S proteins in the presence of $4 \mathrm{mM} \mathrm{GSH}$. C) GSH titration of wild type and C15S proteins in presence of $0.75 \mathrm{mM}$ HED.

In a second set of experiments we compared the ability of the wild type and mutant Grx domains to function as reductants in RNR assays. High specific activity $\left(k_{\text {cat }} 1.4 \pm 0.06 \mathrm{~s}^{-1}\right)$ with an apparent $K_{m}$ for GSH of $1.2 \pm 0.2 \mathrm{mM}$ was only obtained with the wild type protein (Fig. 3). Of the mutant proteins, $\mathrm{C} 12 \mathrm{~S}$ and the $\mathrm{C} 12 \mathrm{~S} / \mathrm{C} 15 \mathrm{~S}$ were deficient in ribonucleotide reduction both with $4 \mathrm{mM}$ and $10 \mathrm{mM} \mathrm{GSH}$, whereas their specific activity was on par with the wild type enzyme when the Grx domain was bypassed using DTT as reductant (Fig. 3C, inset). Interestingly, the C15S mutant promoted a low but significant GSH-dependent 
ribonucleotide reductase activity, as measured both as consumption of NADPH (Fig. 3A) and as formation of dCDP (Fig. 3C), but it was not possible to reach a $V_{\max }$ for the RNR activity of the C15S protein even at $20 \mathrm{mM} \mathrm{GSH}$ (Fig. 3B and data not shown). The GSH concentration of Facklamia spp. is not known, but GSH concentrations in studied bacteria range between 0.1 and $10 \mathrm{mM}$, with Firmicutes generally on the high side (Masip, 2006 \#224;Fahey, 2013 \#183\}. Conceivably, the Grx fused to $F$. ignava NrdB is most efficiently promoting turnover of the $F$. ignava RNR via a dithiol mechanism, and at $10 \mathrm{mM} \mathrm{GSH}$ concentration the $\mathrm{C} 15 \mathrm{~S}$ mutant protein can promote approximately 4-fold less efficient ribonucleotide reduction via a monothiol mechanism involving Cys12 (Fig. S1).
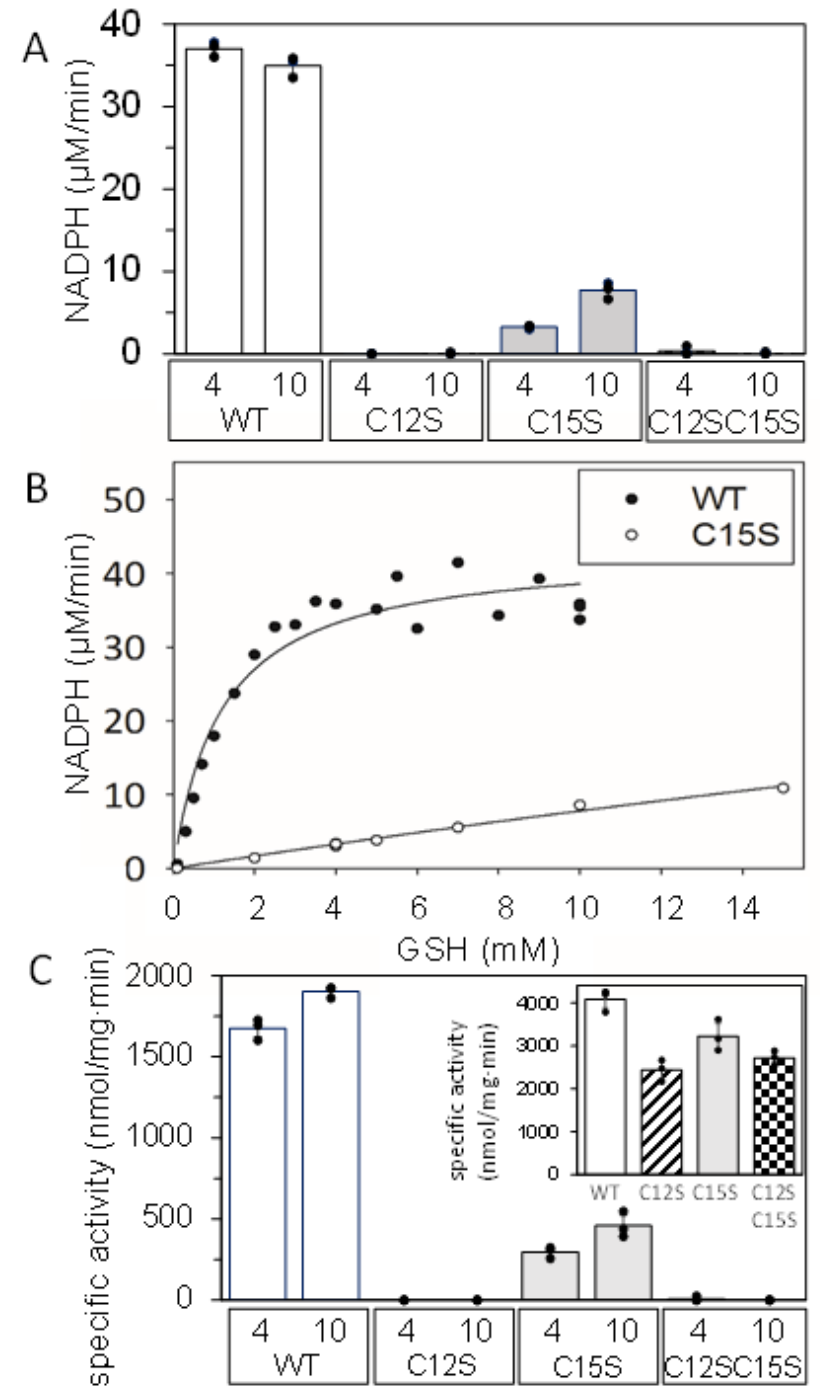

Figure 3. GSH-dependent RNR activity of $F$. ignava NrdB wildtype and mutant proteins. CDP was used as substrate and $3 \mathrm{mM} \mathrm{ATP}$ as effector. A) Enzyme activity measured as NADPH consumption in presence of $0.5 \mu \mathrm{M} \mathrm{NrdB}$. B) GSH-dependent NADPH consumption of the wild type $(\bullet)$ and the C15S (o) NrdB. C) GSH-dependent specific activity measured as dCDP formation. Inset: DTT (10 mM) dependent specific activity measured as dCDP formation. GSH concentrations (4 and $10 \mathrm{mM}$ ) are indicated in A and C. Assays in A and $\mathrm{C}$ were performed in triplicate with standard deviations shown.

\section{Substrate specificity regulation of $F$. ignava RNR via the s-site}

Using a four-substrate activity assay in the presence of saturating concentrations of the substrate specificity site (s-site) effectors ATP, dTTP or dGTP, we found that $F$. ignava RNR 
has a similar specificity regulation pattern to most characterized RNRs (3). ATP stimulated the reduction of CDP and UDP, whereas dTTP stimulated the reduction of GDP, and dGTP stimulated the reduction of ADP and GDP (Fig. 4). There is also a low activity of predominantly CDP reduction in the absence of allosteric effectors. Using mixtures of allosteric effectors, we observed that dTTP-induced GDP reduction increased in the presence of ATP (data not shown), as is commonly seen in RNRs (3).

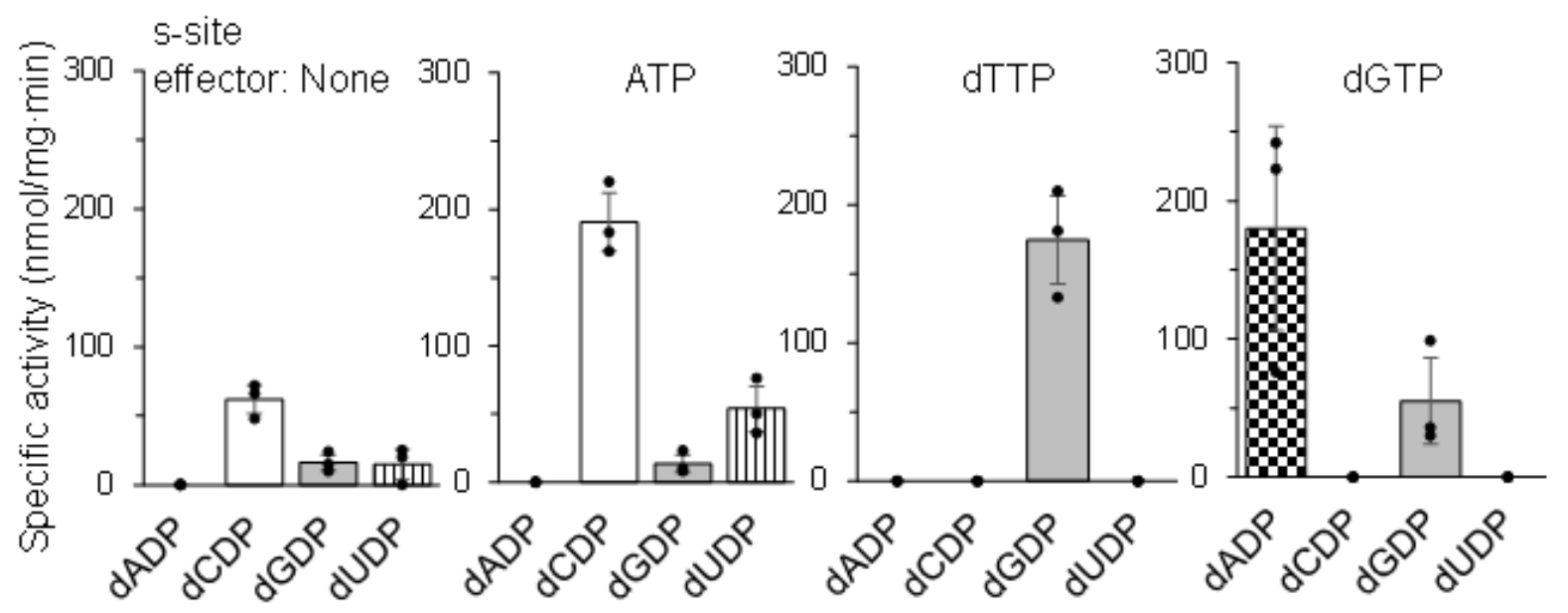

Figure 4. Substrate specificity of $\boldsymbol{F}$. ignava class I RNR. Enzyme assays were performed in mixtures with $0.5 \mathrm{mM}$ of each of the four substrates (ADP, CDP, GDP, UDP) and a saturating concentration of one effector nucleotide at a time. Assays were performed in triplicate with standard deviations shown.

\section{Overall activity of $F$. ignava RNR is regulated via the NrdB-linked ATP-cone}

We performed a series of activity assays with CDP as substrate to elucidate the potential roles of ATP and dATP in activating and inhibiting the enzyme. The presence of ATP activated the enzyme, while dATP showed a dual effect and activated the enzyme when used at low concentrations and was inhibitory at $3 \mu \mathrm{M}$ and higher (Fig. S2). The kinetics are complex, as ATP and dATP can bind both to the s-site in NrdA as well as the ATP-cone in $\mathrm{NrdB}$. To analyze the effects of ATP or dATP at the ATP-cone of NrdB, the specificity site of NrdA was saturated with dTTP and GDP was used as substrate, giving a starting specific activity (normalized to $100 \%$ in Fig. 5) even in the absence of added ATP. In wild type NrdB $K_{L}$ for ATP-dependent activation was $47 \pm 12 \mu \mathrm{M}$ (Fig. 5A), and $K_{i}$ for dATP-dependent inhibition was $1.3 \pm 0.23 \mu \mathrm{M}$ (Fig. $5 \mathrm{~B}$ ). The activity of the deletion mutant that lacks both the Grx domain and the ATP-cone (NrdB $\Delta 169)$ was not affected by addition of either ATP or dATP (Fig. 5A,B). The initial $k_{\text {cat }}$ of the NrdB $\Delta 169$ in the presence of dTTP-loaded NrdA was $2.2 \mathrm{~s}^{-1}$, i.e. almost 3 times higher than that of full-length $\operatorname{NrdB}\left(0.8 \mathrm{~s}^{-1}\right)$, however ATP addition increased the activity of wild type $\mathrm{NrdB}$ to $1.8 \mathrm{~s}^{-1}$ (Fig. $5 \mathrm{~A}$ ); i.e. on par with the $\mathrm{NrdB} \Delta 169$ mutant and other RNR enzymes. Titration with dADP inhibited the wild type enzyme activity (Fig. S3), although less strongly than did dATP. 
Glutaredoxin and ATP-cone fusions to ribonucleotide reductase
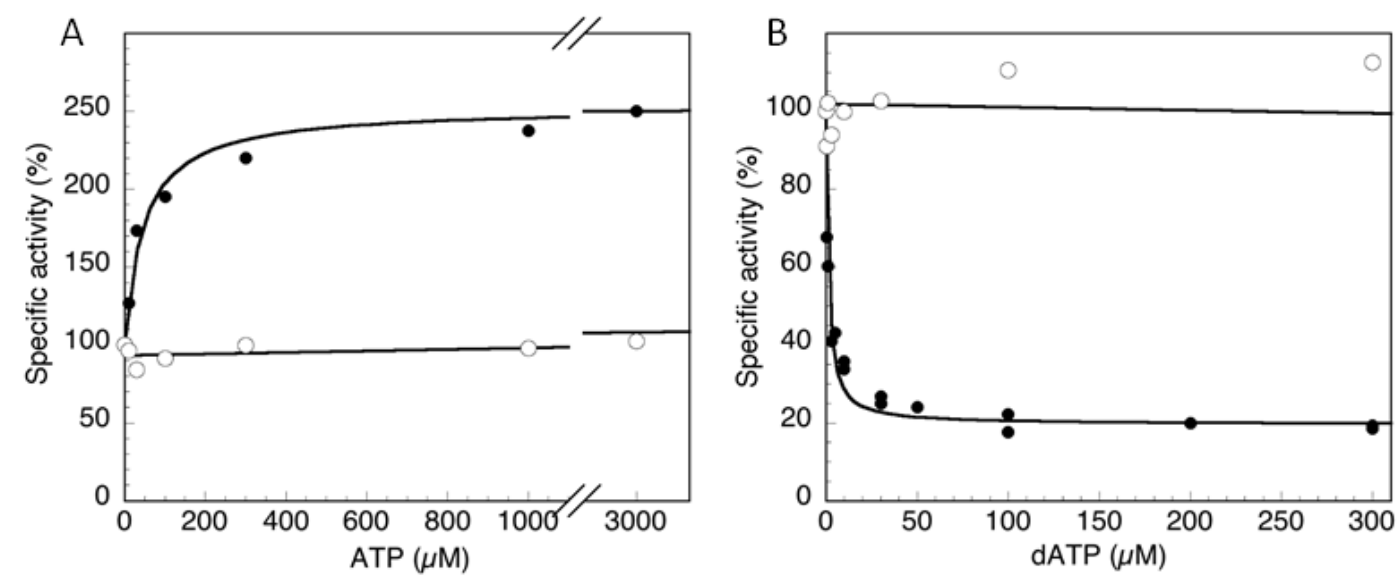

Figure 5. Inhibition and activation of wild type and mutant enzyme activity by dATP and ATP. A) ATP titration, and B) dATP titration of enzyme loaded with $2 \mathrm{mM}$ dTTP and GDP as substrate. Specific activities of NrdB proteins were measured with a 10 -fold excess of NrdA. Wild type NrdB $(\bullet)$ had a starting activity of $830 \pm 120 \mathrm{nmol} / \mathrm{min} \bullet \mathrm{mg}$ in the absence of added ATP and reached a $V_{\max }$ of $1850 \pm 200 \mathrm{nmol} / \mathrm{min} \cdot \mathrm{mg}\left(k_{\text {cat }}=1.8 \mathrm{~s}^{-1}\right)$ in presence of ATP, whereas NrdB $\Delta 169$ ( () had a specific activity of $3400 \pm 500 \mathrm{nmol} / \mathrm{min} \cdot \mathrm{mg} \quad\left(k_{\text {cat }}=2.2 \mathrm{~s}^{-1}\right)$ in the absence of ATP that was not affected by addition of ATP or dATP.

\section{dATP binding to NrdB induces formation of higher oligomeric complexes}

To elucidate the mechanism of allosteric overall activity regulation governed by the NrdBlinked ATP-cone, oligomer-distribution experiments were performed by gas-phase electrophoretic macromolecule analysis (GEMMA). GEMMA analysis showed that the NrdB subunit $(\beta)$ is in a dimer-tetramer equilibrium and the tetramer formation is stimulated by dATP and suppressed by ATP (Fig. 6A). If the ATP-cone is removed as in NrdB $\Delta 169$, the protein loses the ability to form tetramers, indicating that the process is dependent on the ATP-cone (Fig. 6B). In the Grx deletion mutant the ability to form tetramers is decreased but not lost completely (Fig. 6B). The NrdA subunit $(\alpha)$ is in a monomer-dimer equilibrium favoring dimers, especially in the presence of dATP where the monomers are below the detection limit (Fig. 6C). When both proteins were mixed together with dATP, an additional peak corresponding to an $\alpha_{2} \beta_{4}$ complex appeared and to a minor extent also an $\alpha_{4} \beta_{4}$ complex (Fig. 6D). In the absence of allosteric effectors or in the presence of ATP, $\alpha_{2} \beta_{2}$ complexes were formed instead. The subunit compositions of the 234,344 and $470 \mathrm{kDa}$ peaks were determined by comparing the results with each subunit alone. NrdB tetramer formation is very inefficient in the absence of effectors or in the presence of ATP, indicating that the 234 peak only to a minor extent can be explained by NrdB tetramers and to most part contains $\alpha_{2} \beta_{2}$ complexes, which is the result if the major two species $\mathrm{NrdA}$ and $\mathrm{NrdB}$ dimers interact with each other. In the presence of dATP, the two major species NrdA dimers and NrdB tetramers interact to form the $\alpha_{2} \beta_{4}$ complex and to some extent also an $\alpha_{4} \beta_{4}$ complex if an additional NrdA dimer binds. 

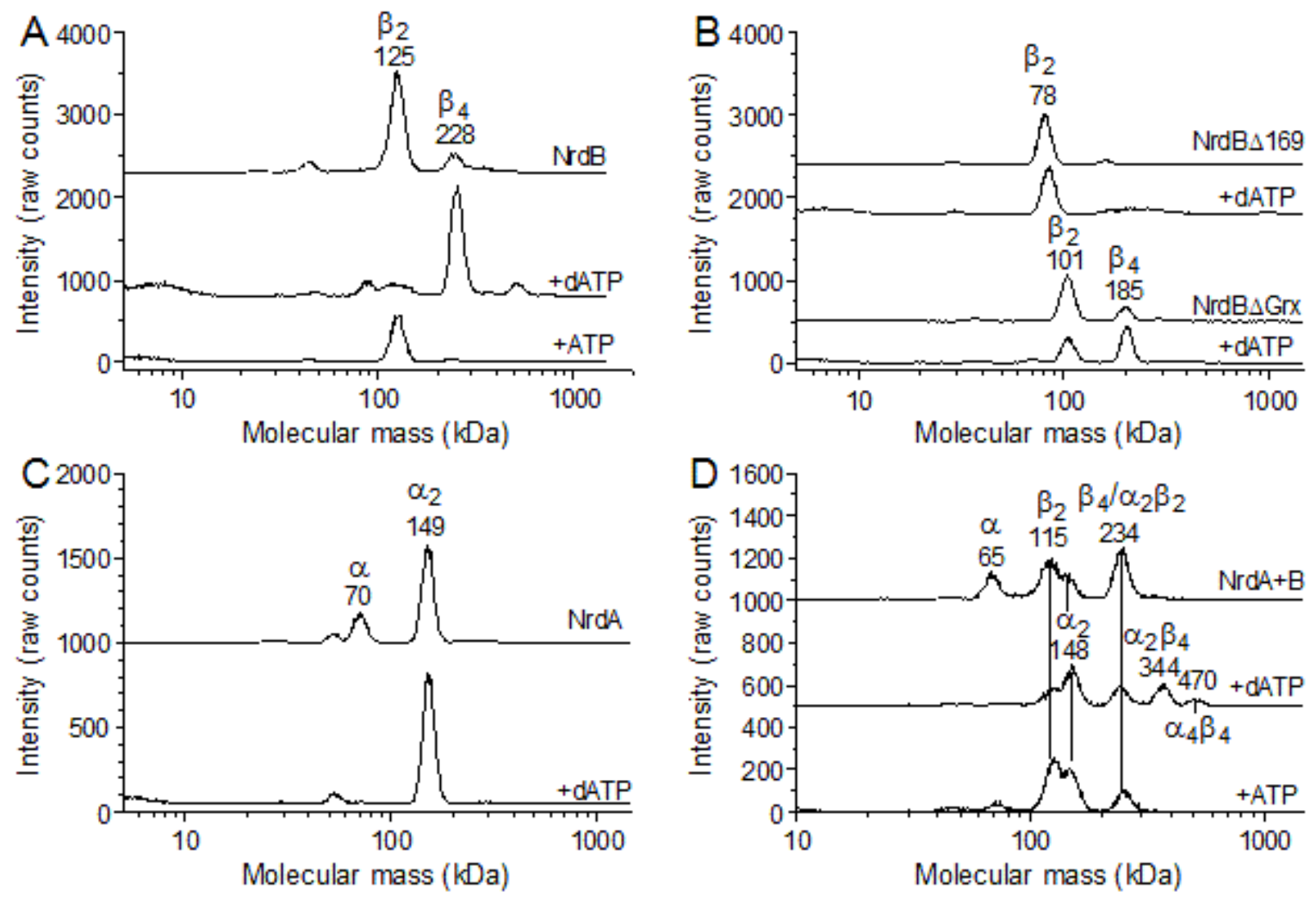

Figure 6. GEMMA analysis of the $\boldsymbol{F}$. ignava ribonucleotide reductase. A) Analysis of $0.05 \mathrm{mg} / \mathrm{ml} \mathrm{NrdB}(0.9 \mu \mathrm{M})$ in the absence or presence of $50 \mu \mathrm{M}$ dATP or $100 \mu \mathrm{M}$ ATP. B) Similar experiments as in A but with NrdB mutant proteins lacking the ATP cone (NrdB $\Delta 169)$ or the Grx domain (NrdB $\Delta \mathrm{Grx}$ ) analyzed with and without $50 \mu \mathrm{M}$ dATP. C) Analysis of 0.05 $\mathrm{mg} / \mathrm{ml} \mathrm{NrdA}$ protein in the absence or presence of $50 \mu \mathrm{M}$ dATP. D) Experiments with NrdANrdB mixtures containing $0.025 \mathrm{mg} / \mathrm{ml}$ of each protein and no effector, $50 \mu \mathrm{M}$ dATP or 100 $\mu \mathrm{M}$ ATP.

To complement the GEMMA analyses of oligomer formation, we performed analytical size exclusion chromatography (Fig. 7) using higher protein concentrations and physiologically reasonable concentrations of effectors ( $3 \mathrm{mM}$ ATP and $0.1 \mathrm{mM} \mathrm{dATP})(28,29)$. The SEC experiments confirmed the GEMMA results. The NrdA protein was a dimer and this ability was enhanced by binding of dATP as well as ATP to its s-site (Fig. 7A). The NrdB subunit doubled in mass in the presence of dATP as compared to ATP, supporting the GEMMA result that it is a dimer with ATP and tetramer with dATP (Fig. 7B). In SEC, both the dimer and tetramer had larger masses than expected, indicating that the shape of the protein is not perfectly globular. Without effector, the NrdB protein seems to be a dimer that gradually goes through a transition to a larger species at higher protein concentration (Fig. 7B). This is in agreement with the GEMMA results that there is a dimer-tetramer equilibrium with the majority of the protein being dimeric (Fig. 6A). When the $\mathrm{NrdA}$ and $\mathrm{NrdB}$ proteins were mixed, they formed an $\alpha_{2} \beta_{2}$ complex with ATP and without effector and a larger species with dATP. There was a gradual movement to a larger species when the protein concentration is increased up to a mass indicating an $\alpha_{4} \beta_{4}$ complex. 

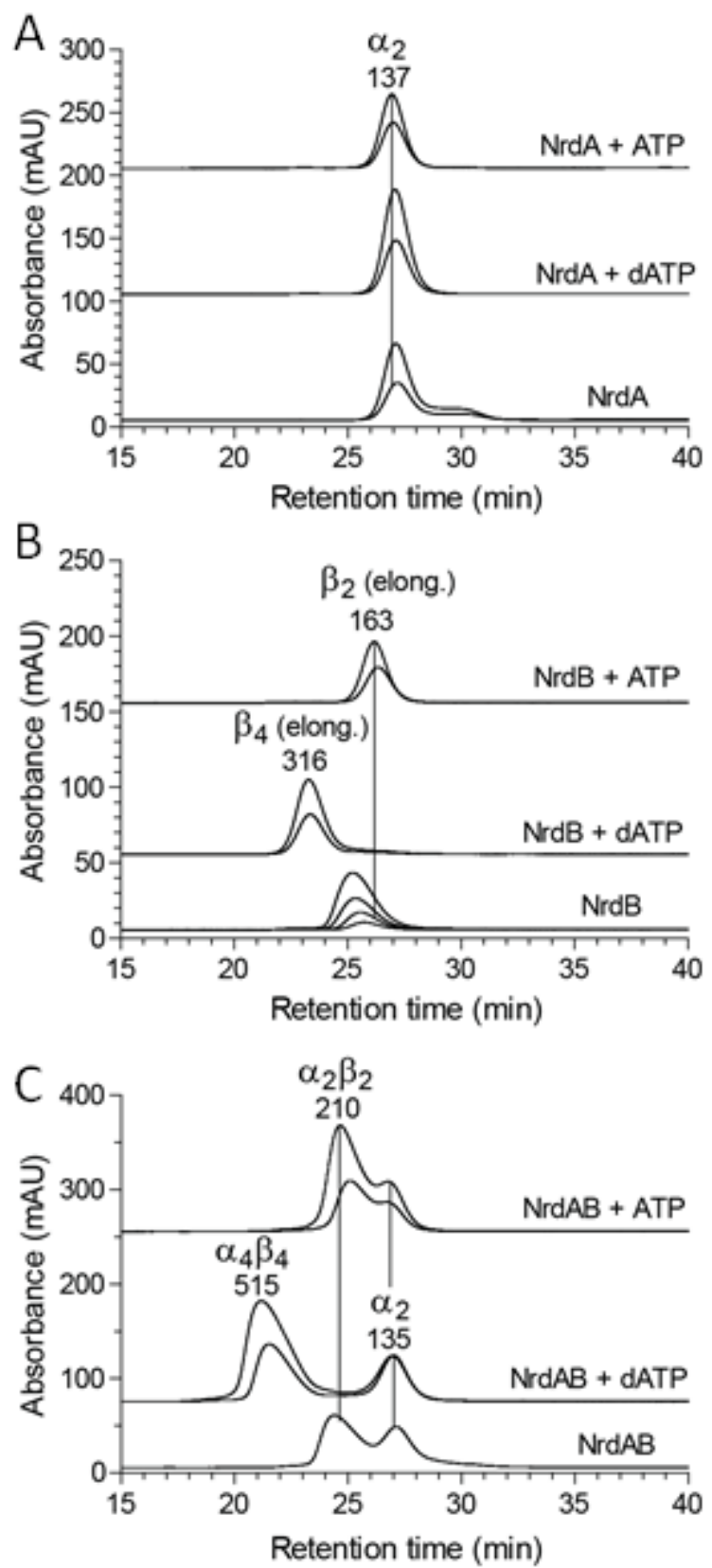

Figure 7. Size exclusion chromatography analysis of $F$. ignava RNR components in the presence of nucleotides. A) 5 and $10 \mu \mathrm{M}$ of the NrdA subunit was analyzed in the presence of $3 \mathrm{mM}$ ATP, $100 \mu \mathrm{M}$ dATP or without effector. B) Corresponding analysis of the NrdB subunit. In this case the experiment without effector was performed at $1.25,2.5,5$ and $10 \mu \mathrm{M}$ protein. The position of the peaks indicate a larger size than expected, which is typical for elongated proteins, and the interpretation above the peaks is based on a comparison with the GEMMA results. C) Analysis of the combination of both subunits. Each subunit was used at 10 and $20 \mu \mathrm{M}$ concentration except in the experiment without effector where only 10 $\mu \mathrm{M}$ was used.

Binding of nucleotides to $F$. ignava $\mathrm{NrdB}$ was investigated using isothermal titration calorimetry (ITC). Binding curves for dATP and ATP to $\mathrm{NrdB}$ at $20^{\circ} \mathrm{C}$ were consistent with a single set of binding sites (Fig. 8). In dATP titrations the fitted apparent $N$ value was significantly above one $(\mathrm{N}=1.4 \pm 0.1)$, suggesting that the protein binds two dATP molecules per ATP-cone provided our preparation contains approximately $70 \%$ active protein. Fit of ATP titrations, performed with the same protein preparation and at the same day resulted in $\mathrm{N}=0.55 \pm 0.02$, suggesting binding of only one ATP per ATP-cone. $K_{d}$ for the different 
nucleotides (Fig. 8E) indicated a 20-fold lower affinity for ATP compared to dATP. Thermodynamic parameters (Fig. 8E) indicated that the interactions are predominantly enthalpy driven, with negative $\Delta \mathrm{H}$ values of -80 and $-60 \mathrm{~kJ} / \mathrm{mol}$ for $\mathrm{dATP}$ and ATP, respectively. As earlier observed for $L$. blandensis NrdB (8) dADP also binds to the ATPcone of $F$. ignava $\mathrm{NrdB}$ with a $K_{d}$ of $5.8 \mu \mathrm{M}$ at $25^{\circ} \mathrm{C}$, i.e. considerably weaker than the $K_{d}$ for dATP (Fig. S4).

We performed an additional set of ITC experiments at $10^{\circ} \mathrm{C}$, which resulted in lower $K_{d}$ values $(0.4 \mu \mathrm{M}$ for dATP and $6.8 \mu \mathrm{M}$ for ATP) but otherwise similar conclusions. Fitted stoichiometries were $1.5 \pm 0.1$ for dATP and $0.57 \pm 0.01$ for ATP in agreement with the $20^{\circ} \mathrm{C}$ results and underscoring our interpretation that the $F$. ignava NrdB protein binds two molecules of dATP and one molecule of ATP.
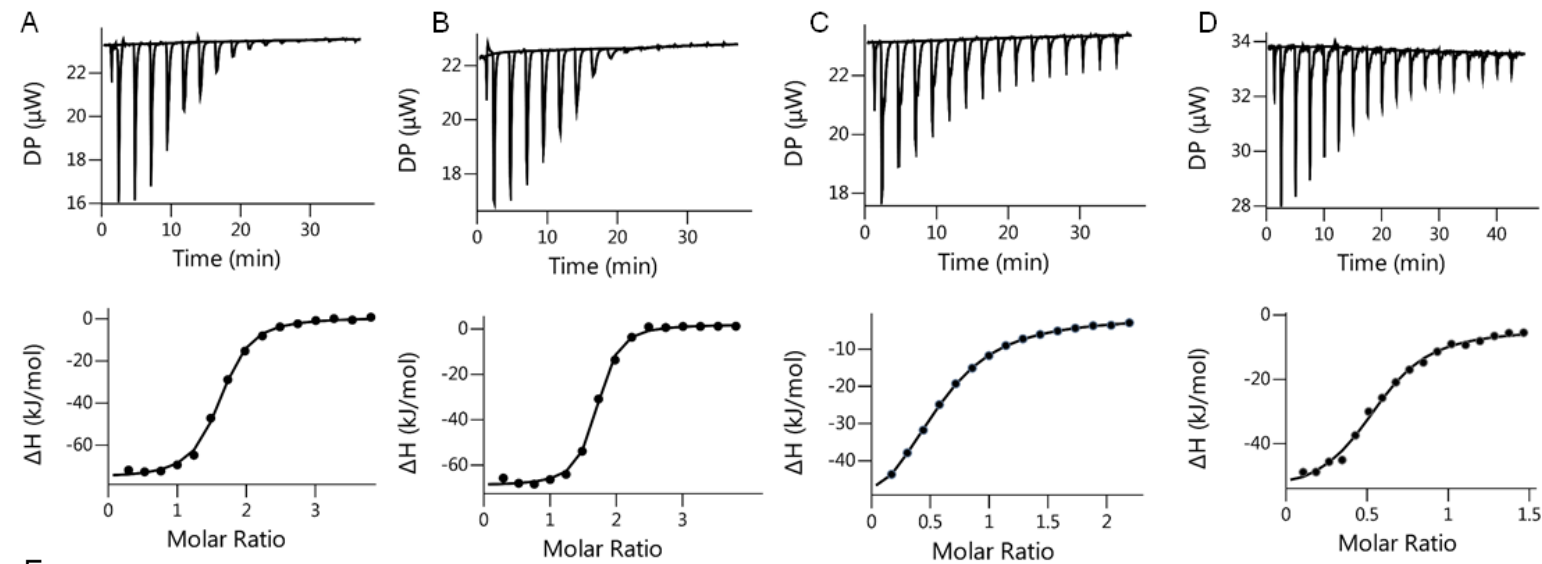

$E$

\begin{tabular}{cccccccc} 
protein & ligand & $\begin{array}{c}\text { Temp } \\
\left({ }^{\circ} \mathrm{C}\right)\end{array}$ & $\mathrm{N}$ & $\mathrm{K}_{\mathrm{d}}(\mu \mathrm{M})$ & $\Delta \mathrm{H}(\mathrm{kJ} / \mathrm{mol})$ & $\Delta \mathrm{G}(\mathrm{kJ} / \mathrm{mol})$ & $-\mathrm{T} \Delta S(\mathrm{~kJ} / \mathrm{mol})$ \\
\hline NrdB & dATP & 20 & $1.4 \pm 0.1$ & $0.85 \pm 0.04$ & $-80 \pm 2$ & -34 & $46 \pm 2$ \\
NrdB & dATP & 10 & $1.5 \pm 0.1$ & $0.4 \pm 0.03$ & $-72 \pm 1$ & -35 & $38 \pm 1$ \\
NrdB & ATP & 20 & $0.55 \pm 0.02$ & $19 \pm 1.2$ & $-60 \pm 1$ & -27 & $33 \pm 1$ \\
NrdB & ATP & 10 & $0.57 \pm 0.01$ & $6.8 \pm 0.86$ & $-52 \pm 2$ & -28 & $24 \pm 2$
\end{tabular}

Figure 8. Representative ITC thermograms obtained by titration of ligands into NrdB. A) Titration of dATP to $\mathrm{NrdB}$ at $20^{\circ} \mathrm{C}$, and B) titration of dATP to $\mathrm{NrdB}$ at $10^{\circ} \mathrm{C}$. C) Titration of ATP to $\mathrm{NrdB}$ at $20^{\circ} \mathrm{C}$, and D) titration of $\mathrm{ATP}$ to $\mathrm{NrdB}$ at $10^{\circ} \mathrm{C}$. Isothermal calorimetric enthalpy changes are shown. E) Thermodynamic parameters of ligand binding to NrdB. Binding isotherms were fitted using a one-set-of sites binding model. All titrations were performed at $20^{\circ} \mathrm{C}$ and $10^{\circ} \mathrm{C}$ as described in Materials and methods.

\section{Type of radical cofactor in the $F$. ignava NrdB protein}

To elucidate the nature of the radical cofactor in the $F$. ignava NrdB protein we employed electron paramagnetic resonance (EPR) spectroscopy. X-band EPR spectra recorded on samples of $\mathrm{NrdB} \Delta 169$ expressed in the presence of excess $\mathrm{Mn}^{2+}$ and purified via affinity chromatography revealed an intense multiline signal with a signal width of $125-130 \mathrm{mT}$ (Fig. 9). The signal varies in a uniform fashion in the interval 5 to $15 \mathrm{~K}$ and is thus attributed to a single paramagnetic species (Fig. 9, compare 5, 10 and $15 \mathrm{~K}$ spectra). Increasing the temperature further resulted in a complete disappearance of the signal at $30 \mathrm{~K}$, with no new signal appearing. The shape, width and temperature dependence of the signal is in good agreement with an anti-ferromagnetically coupled $\mathrm{Mn} \mathrm{n}^{\mathrm{III}} / \mathrm{Mn}^{\mathrm{IV}}$ complex, where the complex line shape is a result of an $S=1 / 2$ system where the unpaired electron is interacting with two $I=$ $5 / 2 \mathrm{Mn}$ centers. In a biological context, similar $\mathrm{Mn}^{\mathrm{III}} / \mathrm{Mn}^{\mathrm{IV}}$ species have been observed in the 
case of superoxidized $\mathrm{Mn}$-catalase and as a short-lived intermediate during the assembly of the $\mathrm{Mn}^{\mathrm{III}}{ }_{2} \mathrm{Y}^{\bullet}$ cofactor in $\mathrm{NrdF}(30,31)$. The presence of such an intense multiline signal in our purified samples suggests that this high-valent species is stable at least on an hours timescale.

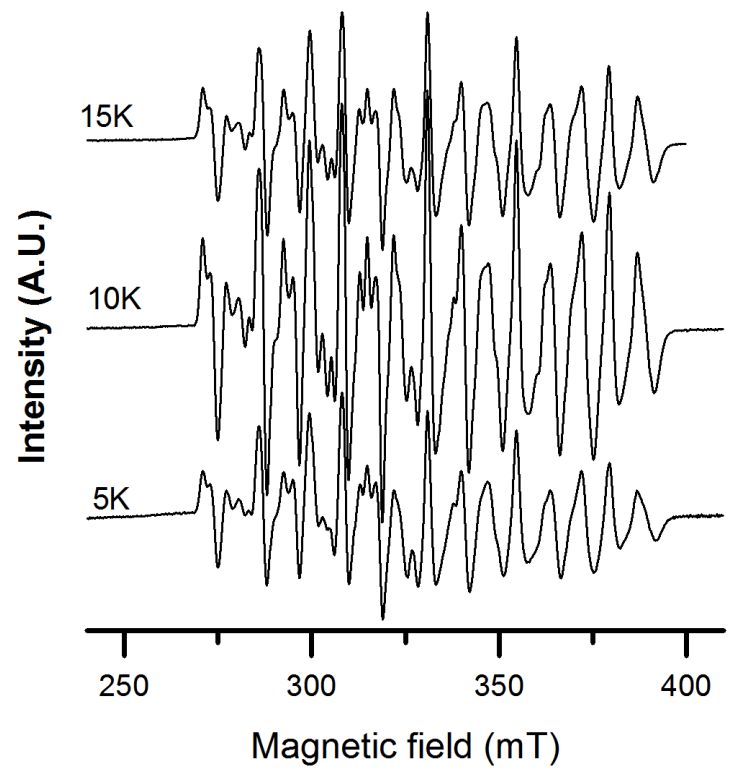

Figure 9. X-band EPR spectra of $F$. ignava NrdB $\Delta 169$ recorded at $5-15 \mathrm{~K}$. Samples recorded on $1.13 \mathrm{mM}$ protein. Instrument settings: microwave frequency $9.28 \mathrm{GHz}$, modulation amplitude 10G, modulation frequency $100 \mathrm{kHz}$, microwave power $1 \mathrm{~mW}$, temperature $5-15 \mathrm{~K}$.

\section{RNR activity in mixtures of $F$. ignava and $L$. blandensis NrdA and NrdB proteins}

The NrdB core of the firmicute F. ignava from residue 170 and onwards has extensive similarity $(61 \%$ sequence identity, Fig. S5) to the core of the NrdB protein from the flavobacterium $L$. blandensis. They both harbor a mixed valent $\mathrm{Mn}_{2}{ }^{11 / / \mathrm{V}}$ center with capacity to initiate the radical-based enzyme reaction (this study and (8)). Both the $F$. ignava NrdB and the L. blandensis NrdB also harbor an ATP-cone domain that functions as an on/off switch for the activity of its RNR holoenzyme by forming tetrameric NrdB structures in presence of dATP to which the NrdA protein is prevented from binding in a productive fashion (above and (8)). However, the ATP-cones of F. ignava and L. blandensis NrdB proteins are more different (28\% sequence identity, Fig. S5) and only aligns extensively over their C-terminal sequences, which in the L. blandensis structure has been shown to interact primarily with one of the two bound dATP molecules (8). The similarity between the two corresponding NrdA proteins is extensive ( $61 \%$ sequence identities, Fig. S6). Based on these similarities we designed a set of experiments to test whether RNR enzyme activity can be achieved in heterologous mixtures of $F$. ignava and $L$. blandensis $\mathrm{NrdA}$ and $\mathrm{NrdB}$ proteins and whether the unique Grx domain would disturb a heterologous interaction. Heterologous mixtures of class I RNR subunits have primarily been tested for distantly related enzymes, e.g. class I RNR subunits from $E$. coli and bacteriophage T4 with negative results (32). On the other hand, several thioredoxins are known to cross-react with heterologous RNRs, whereas Grxs usually do not (33).

Figure 10 shows that the heterologous $F$. ignava NrdA/L. blandensis NrdB holoenzyme is active and regulated by ATP and dATP via the ATP-cone linked to $L$. blandensis NrdB, whereas the heterologous $L$. blandensis NrdA/F. ignava NrdB holoenzyme is inactive. The same is true for heterologous mixtures with $F$. ignava $\mathrm{NrdB} \Delta \mathrm{Grx}$, as well as for $F$. ignava $\operatorname{NrdB} \Delta 169$ (Fig. 10A). $K_{L}$ for ATP is $\approx 300 \mu \mathrm{M}$ and $K_{i}$ for dATP is $\approx 70 \mu \mathrm{M}$ for the ATP-cone of 
L. blandensis $\mathrm{NrdB}$ in the heterologous mixture (Fig. 10B), i.e. more than 3-times higher than the $K_{L(A T P)}$ of $96 \mu \mathrm{M}$ and the $K_{i(d A T P)}$ of $20 \mu \mathrm{M}$ for the L. blandensis holoenzyme (8). The $V_{\max }$ obtained in the heterologous holoenzyme is $250 \mathrm{nmol} / \mathrm{min} \cdot \mathrm{mg}$, corresponding to a $k_{\text {cat }}$ of approximately $0.2 \mathrm{~s}^{-1}$, approximately a fourth of the activity of the L. blandensis holoenzyme (Fig. 10A).
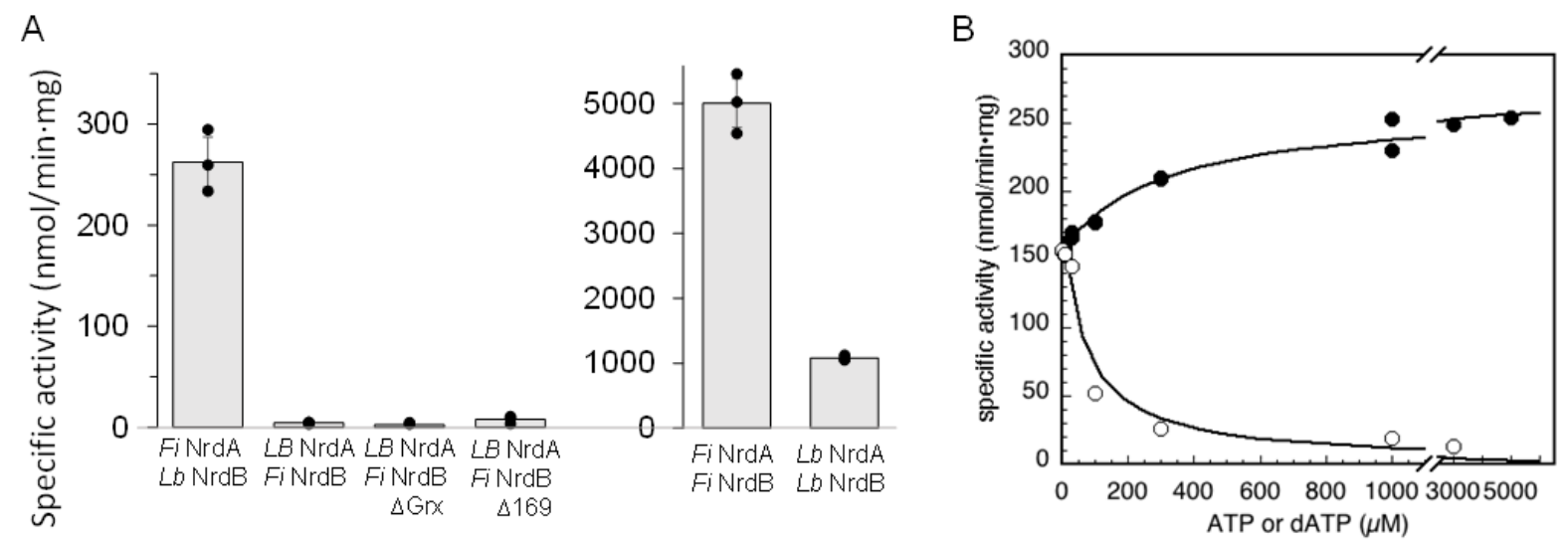

Figure 10. Enzyme activity in heterologous mixtures of NrdA and NrdB protein from $F$. ignava and $L$. blandensis. A) GDP reduction in presence of dTTP as effector. Assays were performed in triplicate with standard deviations shown. B) ATP $(\bullet)$ and dATP (०) titrations of $F$. ignava NrdA plus L. blandensis $\mathrm{NrdB}$ in presence of $2 \mathrm{mM}$ dTTP and with GDP as substrate. ATP and dATP titrations in assays with CDP as substrate are shown in Fig. S7.

\section{Discussion}

We have shown that the multidomain radical-generating component of the $F$. ignava class I RNR contains a gene fusion of an N-terminal Grx that is fully functional as a reductant of the RNR holoenzyme, and an ATP-cone that serves as a general on/off-switch of the enzyme. We also identified fusions of Grx-domains with NrdB proteins in Francisella spp., Allofrancisella guangzhouensis and several viruses (Fig. 1, Table S1), but none of the other cases were with the $\mathrm{NrdBi}$ subclass that the $F$. ignava protein belongs to. This strongly suggests that the $F$. ignava grx::nrdBi fusion was a separate evolutionary event, not related to the grx::nrdB fusions discovered in other organisms and viruses. On the contrary, the presence in F. ignava of a fusion between an ATP-cone domain and NrdBi appears to be the result of horizontal gene transfer since the majority of ATP-cones fused with $n r d B i$ genes occur in flavobacteria (8). It thus appears most parsimonious to suggest that the ATPcone::NrdBi fusion gene was first transferred to $F$. ignava and the gene was subsequently fused with the grx gene in the $F$. ignava genome.

Grx was first described as a physiological reductant for RNR in Escherichia coli (25), and has since also been observed to be involved in sulfate assimilation, detoxification, as well as development and proliferation, primarily in eukaryotic cells $(26,34)$. Similarly to other redoxins, the active site of dithiol Grxs consists of a cysteine pair separated by two residues (predominantly -CPYC-) (26). The corresponding sequence in F. ignava Grx::NrdB is CPWC- (Fig. S5). Grxs differ from other redoxins in that they form mixed disulfides with GSH and also promote glutathionylation/deglutathionylation reactions, which may lead to reduction of protein disulfides (34). E. coli $\mathrm{Grx}$ has been shown to use the dithiol mechanism in its reduction of $E$. coli RNR, whereas a human Grx was interpreted to reduce mammalian RNR via a glutathionylation mechanism (27). However, recent theoretical studies as well as thorough experimental studies on Grx-dependent reduction of protein disulfides with heterologous components from eukaryotic and bacterial origins show that the monothioldithiol mechanisms occur in parallel and that GSH concentration and dominance of specific 
steps in the mechanism determines the preferred path taken (35-37). In this study we show that the Grx::NrdB fusion protein of $F$. ignava can reduce its class I RNR holoenzyme via a dithiol mechanism, and that the C15S mutant in the Grx active site can reduce RNR less efficiently via a monothiol mechanism (Fig. S1). To our knowledge this is the first demonstration of parallel dithiol-monothiol reduction mechanisms in a native system between Grx and its oxidized substrate from the same species..

Over and above the fused Grx domain, the remarkable $F$. ignava NrdB protein exhibits two other unusual characters: a fused ATP-cone and a mixed valent $\mathrm{Mn}_{2}{ }^{11 / 1 / \mathrm{V}}$ metal site. Both of these features have been recently observed in L. blandensis $\mathrm{NrdB}$ and in several $\mathrm{NrdBi}$ proteins in Flavobacteriales (8). The ATP-cone in F. ignava NrdB binds 2 dATP molecules like the cone in $L$. blandensis $\mathrm{NrdB}$, but their amino acid sequences across the ATP-cones are surprisingly dissimilar in the N-terminal half (Fig. S5). This may relate to our finding that the cone in F. ignava binds only one ATP molecule, whereas the cone in L. blandensis binds 2 ATP-molecules. The ATP-loaded active $F$. ignava holoenzyme is $\alpha_{2} \beta_{2}$, whereas the dATPinhibited complexes are $\beta_{4}$ for $\mathrm{NrdB}$, and $\alpha_{2} \beta_{4}$ plus $\alpha_{4} \beta_{4}$ for the holoenzyme. All of these complexes were also observed in the L. blandensis RNR (8).

The mixed valent $\mathrm{Mn}_{2}{ }^{11 / 1 / \mathrm{V}}$ metal site in $F$. ignava $\mathrm{NrdB}$ has a distinct EPR signal in the temperature range of $5-15 \mathrm{~K}$, with no other Mn-related EPR signals at $30 \mathrm{~K}$ and no trace of a tyrosyl radical. A similar high valent $\mathrm{Mn}$ dimer was recently found to be present in NrdB from L. blandensis (8). Later, Boal and co-workers also reported a similar multiline signal in Flavobacterium johnsoniae class I RNR (9). However, in both of these latter cases the multiline feature represented only a fraction of the total metal content. Conversely, in our $F$. ignava $\mathrm{NrdB}$ samples presented here, the $\mathrm{Mn}_{2}{ }^{111 / \mathrm{V}}$ signal is clearly the dominant metal species. These observations underscore the catalytic relevance of the $\mathrm{Mn}_{2}{ }^{11 / / \mathrm{V}}$ site, and support the notion that the NrdBi proteins represent a new subclass of class I RNRs, denoted subclass Id $(6,8,9)$.

The similarities between $F$. ignava and $L$. blandensis NrdB proteins is further manifested by the enzyme activity observed in a heterologous mixture of $F$. ignava $\mathrm{NrdA}$ and $L$. blandensis $\mathrm{NrdB}$, which is almost a third of that in the L. blandensis holoenzyme. Conversely, heterologous mixtures of $L$. blandensis $\mathrm{NrdA}$ and F. ignava NrdB lacks activity even in absence of the Grx domain or for the NrdB $\Delta 169$ protein that lacks both the Grx domain and the ATP-cone. The $F$. ignava NrdB core may have undergone significant structural changes in order to accept the fusion of the Grx domain, which may also pertain to the divergent $\mathrm{N}$ terminal of the ATP-cone sequence. Future studies will be directed to clarify this point.

All in all, we have shown that the unique NrdB protein in F. ignava carries an N-terminal Grx domain with capacity to act as a physiological reducant of its corresponding holoenzyme via a dithiol mechanism and less efficiently via a monothiol mechanism in the C15S mutant variant. The ATP-cone domain, which is fused between the Grx domain and the NrdB core functions as an allosteric on/off switch, promoting an enzymatically active $\alpha_{2} \beta_{2}$ in presence of ATP and enzymatically inactive $\alpha_{2} \beta_{4}$ and $\alpha_{4} \beta_{4}$ complexes in presence of dATP. The radical cofactor in $F$. ignava NrdB is a mixed valent dinuclear $\mathrm{Mn}^{\text {III/IV }}$ site, which forms in the absence of an Nrdl activase and lacks a tyrosyl radical. F. ignava NrdB is an enthralling illustration of how RNR subclasses continuously evolve via gain and loss of accessory domains and RNRrelated proteins. 


\section{Experimental procedures}

\section{Bioinformatics}

The RefSeq database (38) was downloaded 16 March 2018 and searched with the Pfam (39) profiles for Grx (PF00462) and the ATP-cone (PF03477) plus inhouse developed profiles for RNR proteins (http://rnrdb.pfitmap.org) using the HMMER software version 3.1b2 (40). For RNR proteins, only hits covering at least $90 \%$ of the length of the profile were kept. For the Grx and ATP-cone profiles, only hits with a higher bitscore than the Pfam specified GA scores (21.50 in both cases) were kept.

\section{Cloning}

DNA fragments encoding NrdAi (WP_006702002) and NrdBi (EKB53615/WP_006702003) were amplified by PCR from Facklamia ignava CCUG 37419 genomic DNA, obtained from the Culture Collection, University of Gothenburg using specific primers:

NrdA: FiR1 For 5'- tctcCATATGACCGCACAATTAAAGAATC-3' and

FiR1_Rev 5'- cagaGGATCCTTAAGCTTCACAAGCTAAGC -3'.

NrdB: FiR2 For 5'- tctaCATATGACTCAAGTACAAGTTTATAG-3',

FiR2_REV 5'- cagaGGATCCTTAGAATAGGTCGTCGGC-3',

The $\mathrm{PCR}$ products were purified, cleaved with Ndel and BamHI restriction enzymes and inserted into a pET-28a(+) expression vector (Novagen, Madison, Wisconsin, USA). The obtained constructs $\mathrm{pET}$-nrdA and $\mathrm{pET}$-nrdB contained an N-terminal hexahistidine (His) tag and thrombin cleavage site. To construct the truncated NrdB mutant, lacking the Grx domain (residues 1-78), new forward primer FiR2 $\triangle$ Grx_For 5'tctaCATATGAGCAAAATCCCGCAACAC -3' was used with FiR2_REV to yield a pET$\operatorname{nrdB} \Delta \mathrm{Grx}$. To construct the truncated NrdB mutant, lacking both the $\overline{G r x}$ and the entire ATP. cone domains (residues 1-169), new forward primer FiR2 169 _For 5'tctaCATATGGCGCGTCAACGTGATATA -3' was used with FiR2_REV to yield a pET$\operatorname{nrdB} \Delta 169$. The cloning process and the resulting constructs $p \bar{E} T-n r d B \Delta G r x$ and $p E T-$ $\mathrm{nrdB} \Delta 169$ were similar to that of the wild type $\mathrm{pET}$-nrdB, except that they lacked sequences coding for the N-terminal 78 and 169 amino acids respectively. To obtain NrdB bearing point mutations of individual cysteine residues to serines at the Grx active site, pET-nrdB_C12S, pET-nrdB_C15S or the double mutant, were both cysteines were mutated to serines pETnrdB_C12SC15S, constructs containing nucleotide mismatches T34A, G44C and T34AG44C, were ordered from GenScript.

\section{Protein expression}

Overnight cultures of $E$. coli BL21(DE3)/pET28a(+) bearing pET-nrdA, pET-nrdB, pETnrdB $\Delta \mathrm{Grx}, \mathrm{pET}-\mathrm{nrdB} \Delta 169$, pET-nrdB_C12S, pET-nrdB_C15S, pET-nrdB_C12SC15S were diluted to an absorbance at $600 \mathrm{~nm}$ of 0.1 in LB (Luria-Bertani) liquid medium, containing kanamycin $(50 \mu \mathrm{g} / \mathrm{ml})$ and shaken vigorously at $37^{\circ} \mathrm{C}$. At an absorbance of $0.8 \mathrm{~A}_{600}$ isopropyl- $\beta$-D-thiogalactopyranoside (Sigma) was added to a final concentration of $0.5 \mathrm{mM}$; the cultures expressing $\mathrm{NrdB}$ were further supplementented with $\mathrm{MnSO}_{4}$ (final concentration $0.5 \mathrm{mM}$ ) during the induction. The cells were grown overnight at $30^{\circ} \mathrm{C}$ and harvested by centrifugation.

\section{Protein purification}

The cell pellet was resuspended in lysis buffer: $50 \mathrm{mM}$ Tris- $\mathrm{HCl} \mathrm{pH} 7.6$ containing $300 \mathrm{mM}$ $\mathrm{NaCl}, 10 \%$ glycerol, $2 \mathrm{mM}$ DTT, $10 \mathrm{mM}$ imidazole, $1 \mathrm{mM}$ PMSF. Cells were disrupted by high pressure homogenization and the lysate was centrifuged at $18,000 \times \mathrm{g}$ for $45 \mathrm{~min}$ at $4^{\circ} \mathrm{C}$. 
Glutaredoxin and ATP-cone fusions to ribonucleotide reductase

The recombinant His-tagged protein was first isolated by metal-chelate affinity chromatography using ÄKTA prime system (GE Healthcare): the supernatant was loaded on a HisTrap FF Ni Sepharose column (GE Healthcare), equilibrated with lysis buffer (without PMSF), washed thoroughly with buffer and eluted with buffer containing $500 \mathrm{mM}$ imidazole. NrdB_C12S, NrdB_C15S, NrdB_C12SC15S and the wild type NrdB used for measuring the redox activity of the NrdB fused Grx were then applied to the Sephadex G-25 PD10 desalting column equilibrated with buffer containing $50 \mathrm{mM}$ Tris- $\mathrm{HCl} \mathrm{pH} 7.6,300 \mathrm{mM} \mathrm{NaCl}, 10 \%$ glycerol and $1 \mathrm{mM}$ DTT, frozen in liquid nitrogen and stored at $-80^{\circ} \mathrm{C}$ until used.

For $\mathrm{NrdA}, \mathrm{NrdB}, \mathrm{NrdB} \Delta \mathrm{Grx}$ and $\mathrm{NrdB} \Delta 169$ further purification was accomplished by fast protein liquid chromatography (FPLC) on a $125 \mathrm{ml}$ column packed with HiLoad 16/600 Superdex $200 \mathrm{pg}$ column (GE Healthcare) using ÄKTA prime system, equilibrated with buffer containing $50 \mathrm{mM}$ Tris- $\mathrm{HCl} \mathrm{pH} 7.6,300 \mathrm{mM} \mathrm{NaCl}, 10 \%$ glycerol and $2 \mathrm{mM}$ DTT. Eluted protein was collected.

NrdA was further applied to HIC chromatography using the HiLoad 16/60 phenyl sepharose

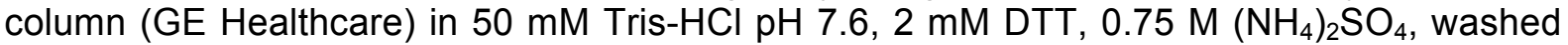
extensively (15 column volumes) with the same buffer and eluted with buffer without ammonium sulphate. The protein was resuspended in excess of buffer containing $50 \mathrm{mM}$ Tris- $\mathrm{HCl} \mathrm{pH} \mathrm{7.6,} 300 \mathrm{mM} \mathrm{NaCl}, 10 \%$ glycerol, $2 \mathrm{mM}$ DTT, concentrated and frozen until used. The HIC chromatography removed residual nucleotide contamination from NrdA.

\section{L. blandensis NrdA and NrdB were expressed and purified as previously described (8)}

Protein concentrations were determined by measuring the UV absorbance at $280 \mathrm{~nm}$ based on protein theoretical extinction coefficients $99700 \mathrm{M}^{-1} \mathrm{~cm}^{-1}$ for $\mathrm{NrdA}, 72770 \mathrm{M}^{-1} \mathrm{~cm}^{-1}$ for $\mathrm{NrdB}$ (and cysteine to serine mutants), $54320 \mathrm{M}^{-1} \mathrm{~cm}^{-1}$ for $\mathrm{NrdB} \Delta \mathrm{Grx}$ and $51340 \mathrm{M}^{-1} \mathrm{~cm}^{-1}$ for $\mathrm{NrdB} \Delta 169$. Protein purity was evaluated by SDS-PAGE $(12 \%)$ stained with Coomassie Brilliant Blue. Proteins were concentrated using Amicon Ultra-15 centrifugal filter units (Millipore), frozen in liquid nitrogen and stored at $-80^{\circ} \mathrm{C}$ until used.

For EPR measurements, NrdB $\triangle 169$, was purified using affinity chromatography as described above but transferred to EPR tubes and flash frozen in liquid nitrogen in EPR tubes immediately upon elution.

\section{Enzyme activity measurements}

Enzyme assays were performed at room temperature in $50 \mathrm{mM}$ Tris- $\mathrm{HCl}, \mathrm{pH} 8$ in volumes of $50 \mu \mathrm{l}$. Reaction conditions, giving maximal activity were determined experimentally. In a standard reaction the constituents were; $10 \mathrm{mM}$ DTT, $40 \mathrm{mM}$ or $20 \mathrm{mM} \mathrm{Mg}\left(\mathrm{CH}_{3} \mathrm{CO}_{2}\right)_{2}$ (when $\mathrm{NrdA}$ of $F$. ignava or L.blandensis was used respectively), $10 \mathrm{mM} \mathrm{KCl}, 0.8 \mathrm{mM} \mathrm{CDP}$, and various concentrations of allosteric effectors ATP or dATP. Mixtures of $0.1 \mu \mathrm{M}$ to $1 \mu \mathrm{M}$ of $\mathrm{NrdB}, 0.07 \mu \mathrm{M}$ NrdB $\Delta 169,0.5 \mu \mathrm{M}$ NrdB_C12S, NrdB_C15S, or NrdB_C12SC15S and a 10fold excess of $\mathrm{NrdA}$ were used. Some components were explicitly varied as indicated in specific experiments.

In experiments aimed to determine the redoxin activity of the NrdB fused Grx, DTT was omitted. Instead, $4 \mathrm{mM}$ or $10 \mathrm{mM}$ reduced $\mathrm{GSH}, 11 \mathrm{\mu g} \mathrm{ml}^{-1}$ glutathione reductase (from yeast, Sigma) and $1 \mathrm{mM}$ NADPH were added to the reaction mixtures. CDP $(0.8 \mathrm{mM})$ was used as substrate and ATP $(3 \mathrm{mM})$ as effector. Protein concentration of $0.5 \mu \mathrm{M}$ for wild type NrdB, NrdB_C12S, NrdB_C15S, or NrdB_C12SC15S were used in combination with $5 \mu \mathrm{M}$ NrdA. 
When dTTP ( $2 \mathrm{mM}$ ) was used as an s-site effector, $0.8 \mathrm{mM}$ GDP was used as substrate. In the four substrate assays, the substrates CDP, ADP, GDP and UDP were simultaneously present in the mixture at concentrations of $0.5 \mathrm{mM}$ each with $2 \mathrm{mM}$ of one of the effectors (ATP, dTTP or dGTP). The substrate mixture was added last to start the reactions.

Enzyme reactions were incubated for 2 to 30 minutes at room temperature and then stopped by the addition of methanol. Substrate conversion was analyzed by HPLC using a Waters Symmetry C18 column $(150 \times 4.6 \mathrm{~mm}, 3.5 \mu \mathrm{m}$ pore size $)$ equilibrated with buffer A. Samples of $25-100 \mu \mathrm{l}$ were injected and eluted at $0.4 \mathrm{ml} / \mathrm{min}$ at $10^{\circ} \mathrm{C}$ with a linear gradient of $0-30 \%$ buffer B over 40 min for the separation of CDP and dCDP or $0-100 \%$ buffer B over 45 min for the separation of GDP and dGDP (buffer A: 10\% methanol in $50 \mathrm{mM}$ potassium phosphate buffer, $\mathrm{pH} 7.0$, supplemented with $10 \mathrm{mM}$ tributylammonium hydroxide; buffer B: $30 \%$ methanol in $50 \mathrm{mM}$ potassium phosphate buffer, $\mathrm{pH} 7.0$, supplemented with $10 \mathrm{mM}$ tributylammonium hydroxide). Compound identification was achieved by comparison with injected standards. Relative quantification was obtained by peak height measurements in the chromatogram (UV absorbance at $271 \mathrm{~nm}$ or $254 \mathrm{~nm}$ ) in relation to standards. Specific activities are given as nmol product formed per min and $\mathrm{mg}$ protein.

From a direct plot of activity versus concentration of effector, the $K_{L}$ values for binding of effectors to the s-site and the a-site, were calculated in SigmaPlot using the equation:

$\mathrm{v}=\mathrm{V}_{\max } \times[\mathrm{dNTP}] /\left(\mathrm{K}_{\mathrm{L}}+[\mathrm{dNTP}]\right)$

and $\mathrm{K}_{\mathrm{i}}$ for non-competitive dATP inhibition at NrdB was calculated in Sigmaplot using the equation:

$\mathrm{v}=\mathrm{V}_{\max } /\left(1+\left([\mathrm{dNTP}] / \mathrm{K}_{\mathrm{i}}\right)\right.$

\section{Photometric activity assays}

Photometric assays for NrdB-fused Grx based on the artificial electron acceptor HED were performed as described in earlier studies $(41,42)$. The standard $\mathrm{Grx}$ assay contains $50 \mathrm{mM}$ Tris $\mathrm{pH} 8.0,0.1 \mathrm{mg} / \mathrm{ml} \mathrm{BSA}, 11 \mu \mathrm{g} \mathrm{ml}^{-1}$ glutathione reductase (from S. cerevisiae), $4 \mathrm{mM}$ glutathione, $0.75 \mathrm{mM} \mathrm{HED}$, and $0.4 \mathrm{mM} \mathrm{NADPH}$. The above ingredients were mixed and incubated for 3 minutes, after which the reaction was started by the addition of $0.1 \mu \mathrm{M}$ wild type or mutant Grx (NrdB fused). Reference cuvette contained all ingredients, except Grx. $A_{340}$ was recorded for $3 \mathrm{~min}$ at room temperature using Lambda 35 UV/VIS spectrophotometer (Perkin Elmers). Linear decrease in $A_{340}$ was used to calculate moles of NADPH consumed using its extinction coefficient of $6220 \mathrm{M}^{-1} \mathrm{~cm}^{-1}$.

The combined redoxin/RNR assays contained $0.5 \mu \mathrm{M}$ NrdB, $5 \mu \mathrm{M} \mathrm{NrdA}$, indicated amount of glutathione, $11 \mathrm{\mu g} \mathrm{ml}^{-1}$ glutathione reductase, $0.25 \mathrm{mM} \mathrm{NADPH}, 10 \mathrm{mM} \mathrm{Mg}\left(\mathrm{CH}_{3} \mathrm{CO}_{2}\right)_{2}, 3 \mathrm{mM}$ ATP. Reaction was started by the addition of $0.8 \mathrm{mM} \mathrm{CDP}$. The reaction was monitored by the change of $A_{340}$ using Cary 60 UV-VIS spectrophotometer (Agilent technologies) Specific activity was calculated using $1 \mathrm{~mol}$ of NADPH equals $1 \mathrm{~mol}$ of formed dCDP.

\section{GEMMA analysis}

In GEMMA, biomolecules are electrosprayed into gas phase, neutralized to singly charged particles, and the gas phase electrophoretic mobility is measured with a differential mobility analyzer. The mobility of an analyzed particle is proportional to its diameter, which therefore allows for quantitative analysis of the different particle sizes contained in a sample (43). The GEMMA instrumental setup and general procedures were as described previously (44). $\mathrm{NrdA}, \mathrm{NrdB}, \mathrm{NrdB} \Delta \mathrm{Grx}$ and $\mathrm{NrdB} \Delta 169$ proteins were equilibrated by Sephadex G-25 
chromatography into a buffer containing $100 \mathrm{mM} \mathrm{NH}_{4} \mathrm{CH}_{3} \mathrm{CO}_{2}$, pH 7.8 and $2 \mathrm{mM}$ DTT. Prior to GEMMA analysis, the protein samples were diluted to a concentration of $0.05 \mathrm{mg} / \mathrm{ml}$ in a buffer containing $20 \mathrm{mM} \mathrm{NH} \mathrm{CH}_{3} \mathrm{CO}_{2}, \mathrm{pH} 7.8,1 \mathrm{mM}$ DTT, $0.005 \%$ (v/v) Tween 20, nucleotides (when indicated), and $\mathrm{Mg}\left(\mathrm{CH}_{3} \mathrm{CO}_{2}\right)_{2}$ (equimolar to the total nucleotide concentration), incubated for $5 \mathrm{~min}$ at room temperature, centrifuged and applied to the GEMMA instrument. The runs were conducted at low flow rate, resulting in $1.4-2$ Psi pressure. The GEMMA system contained the following components: 3480 electrospray aerosol generator, 3080 electrostatic classifier, 3085 differential mobility analyzer, and 3025A ultrafine condensation particle counter (TSI Corp., Shoreview, MN).

\section{Analytical SEC}

The SEC experiments were performed at ambient temperature with a Superdex ${ }^{\mathrm{TM}} 200$ $10 / 300$ column (GE Healthcare) equilibrated with a mobile phase containing $50 \mathrm{mM} \mathrm{KCl}, 10$ $\mathrm{mM} \mathrm{MgCl} 20.1 \mathrm{mM}$ dithiothreitol, and $50 \mathrm{mM}$ Tris- $\mathrm{HCl} \mathrm{pH}$ 7.6. $3 \mathrm{mM}$ ATP or $0.1 \mathrm{mM}$ dATP was also included in the mobile phase when nucleotide-dependent protein oligomerization was studied. The injection loop volume was $100 \mu \mathrm{l}$ and the flow rate was $0.5 \mathrm{ml} / \mathrm{min}$. The UV trace was recorded with a Jasco UV-2075 Plus detector (Jasco Inc., Easton, MD) at $290 \mathrm{~nm}$ to limit the absorbance from the nucleotides, The proteins were incubated in mobile phase for 5 min prior to injection onto the column.

\section{Isothermal titration calorimetry measurements}

Isothermal titration calorimetry (ITC) experiments were carried out on a MicroCal ITC 200 system (Malvern Instruments Ltd) in a buffer containing $50 \mathrm{mM}$ Tris $\mathrm{pH} 7.65,300 \mathrm{mM} \mathrm{NaCl}$, $10 \%$ glycerol, $2 \mathrm{mM}$ tris(2-carboxyethyl)phosphine, and $10 \mathrm{mM} \mathrm{MgCl}_{2}$. Measurements were done at $20^{\circ} \mathrm{C}$ and $10^{\circ} \mathrm{C}$. The initial injection volume was $0.5 \mu \mathrm{l}$ over a duration of $1 \mathrm{~s}$. All subsequent injection volumes were 2-2.5 $\mu$ l over 4-5 s with a spacing of $150-180 \mathrm{~s}$ between the injections. Data for the initial injection were not considered. For dATP binding analysis, the concentration of $\mathrm{NrdB}$ in the cell was $40 \mu \mathrm{M}$ and dATP in syringe $600 \mu \mathrm{M}$. For titration of ATP into NrdB, cell and syringe concentrations were $103 \mu \mathrm{M}$ NrdB and $1.2 \mathrm{mM}$ ATP. The data were analyzed using the built-in one set of sites model of the MicroCal PEAQ-ITC Analysis Software (Malvern Panalytical). Standard deviations in thermodynamic parameters, $\mathrm{N}$ and $K_{d}$ were estimated from the fits of three different titrations.

\section{Electron paramagnetic resonance spectroscopy}

Measurements were performed on a Bruker ELEXYS E500 spectrometer using an ER049X SuperX microwave bridge, in a Bruker SHQ0601 cavity equipped with an Oxford Instruments continuous flow cryostat, and using an ITC 503 temperature controller (Oxford Instruments). The Xepr software package (Bruker) was used for data acquisition and processing of spectra.

\section{Acknowledgments}

We thank Al Claiborne, Wake Forest University, NC, USA, for useful advice on bacillithiol and glutathione biosynthesis, Ann Magnusson and Sigrid Berglund, Uppsala University, Sweden, for valuable discussions on dinuclear manganese centers, llya Borovok, Tel-Aviv University, Israel, for discussions on ATP-cones, and Malvern Panalytical for kindly sharing the MicroCal PEAQ-ITC Analysis Software for the analysis of ITC data. This study was supported by grants from the Swedish Cancer Society (CAN 2016/670 to BMS), the Swedish Research Council (2016-01920 to BMS), the Wenner-Gren Foundations (to BMS) and the Carl Trygger Foundation (to AH). Work in the laboratory of GB is supported by the Swedish Research Council (621-2014-5670), the Swedish Research Council for Environment, 
Glutaredoxin and ATP-cone fusions to ribonucleotide reductase

Agricultural Sciences and Spatial Planning (213-2014-880) and the European Research Council (714102).

\section{Conflict of interest}

The authors declare that they have no conflicts of interest with the contents of this article.

\section{Abbreviations and nomenclature}

a-site, allosteric overall activity site in the ATP-cone; BSA, bovine serum albumin; dNTPs, deoxyribonucleotides; DTT, dithiothreitol; EPR, electron paramagnetic resonance; FPLC, fast protein liquid chromatography; GEMMA, gas-phase electrophoretic macromolecule analysis; Grx, glutaredoxin; GSH, glutathione; HED, 2-hydroxyethyl disulfide; HIC; hydrophobic interaction chromatography; HPLC, high performance liquid chromatography; ITC, isothermal titration calorimetry; $\mathrm{NrdB} \Delta \mathrm{Grx}, \mathrm{NrdB}$ protein lacking $69 \mathrm{~N}$-terminal residues corresponding to the glutaredoxin domain; $\mathrm{NrdB} \Delta 169, \mathrm{NrdB}$ protein lacking the glutaredoxin domain and the ATP-cone domain; PCR, polymerase chain reaction; PMSF, phenylmethylsulfonyl fluoride; RNR, ribonucleotide reductase; SDS-PAGE, sodium dodecyl sulphate polyacrylamide gel electrophoresis; SEC, size exclusion chromatography; s-site, allosteric specificity site in $\mathrm{NrdA}$

\section{References}

1. Lundin, D., Berggren, G., Logan, D. T., and Sjöberg, B. M. (2015) The origin and evolution of ribonucleotide reduction. Life (Basel) 5, 604-636

2. Torrents, E. (2014) Ribonucleotide reductases: essential enzymes for bacterial life. Frontiers in cellular and infection microbiology 4, 52

3. Hofer, A., Crona, M., Logan, D. T., and Sjöberg, B. M. (2012) DNA building blocks: keeping control of manufacture. Crit Rev Biochem Mol Biol 47, 50-63

4. Reichard, P. (2010) Ribonucleotide reductases: substrate specificity by allostery. Biochem Biophys Res Commun 396, 19-23

5. Stubbe, J. (2000) Ribonucleotide reductases: the link between an RNA and a DNA world? Curr Opin Struct Biol 10, 731-736

6. Berggren, G., Lundin, D., and Sjöberg, B.-M. (2017) Homo- and heterometallic dinuclear manganese proteins: active site assembly. in Metalloprotein Active Site Assembly (Johnson, M. K., and Scott, R. A. eds.), John Wiley \& Sons, Ltd. pp

7. Cox, N., Ogata, H., Stolle, P., Reijerse, E., Auling, G., and Lubitz, W. (2010) A TyrosylDimanganese Coupled Spin System is the Native Metalloradical Cofactor of the R2F Subunit of the Ribonucleotide Reductase of Corynebacterium ammoniagenes. J. Am. Chem. Soc. 132, 11197-11213

8. Rozman Grinberg, I., Lundin, D., Hasan, M., Crona, M., Jonna, V. R., Loderer, C., Sahlin, M., Markova, N., Borovok, I., Berggren, G., Hofer, A., Logan, D. T., and Sjöberg, B. M. (2018) Novel ATP-cone-driven allosteric regulation of ribonucleotide reductase via the radical-generating subunit. Elife 7

9. Rose, H. R., Ghosh, M. K., Maggiolo, A. O., Pollock, C. J., Blaesi, E. J., Hajj, V., Wei, Y., Rajakovich, L. J., Chang, W. C., Han, Y., Hajj, M., Krebs, C., Silakov, A., Pandelia, M. E., Bollinger, J. M., Jr., and Boal, A. K. (2018) Structural Basis for Superoxide Activation of Flavobacterium johnsoniae Class I Ribonucleotide Reductase and for Radical Initiation by Its Dimanganese Cofactor. Biochemistry 57, 2679-2693

10. Jiang, W., Yun, D., Saleh, L., Barr, E. W., Xing, G., Hoffart, L. M., Maslak, M. A., Krebs, C., and Bollinger, J. M., Jr. (2007) A manganese(IV)/iron(III) cofactor in Chlamydia trachomatis ribonucleotide reductase. Science 316, 1188-1191

11. Högbom, M., Stenmark, P., Voevodskaya, N., McClarty, G., Gräslund, A., and Nordlund, $P$. (2004) The radical site in chlamydial ribonucleotide reductase defines a new R2 subclass. Science $305,245-248$ 
12. Srinivas, V., Lebrette, H., Lundin, D., Kutin, Y., Sahlin, M., Lerche, M., Eirich, J., Branca, R. M. M., Cox, N., Sjöberg, B. M., and Högbom, M. (2018) Metal-independent ribonucleotide reduction powered by a DOPA radical in Mycoplasma pathogens. submitted

13. Sengupta, R., and Holmgren, A. (2014) Thioredoxin and glutaredoxin-mediated redox regulation of ribonucleotide reductase. World $\mathrm{J}$ Biol Chem 5, 68-74

14. Arnér, E. S., and Holmgren, A. (2000) Physiological functions of thioredoxin and thioredoxin reductase. Eur J Biochem 267, 6102-6109

15. Jordan, A., Åslund, F., Pontis, E., Reichard, P., and Holmgren, A. (1997) Characterization of Escherichia coli $\mathrm{NrdH}$. A glutaredoxin-like protein with a thioredoxinlike activity profile. J Biol Chem 272, 18044-18050

16. Crona, M. (2010) Quaternary structure and interaction approaches to allosteric regulation of class I ribonucleotide reductases, Department of Molecular Biology and Functional Genomics, Stockholm University, Stockholm

17. Kingry, L. C., and Petersen, J. M. (2014) Comparative review of Francisella tularensis and Francisella novicida. Frontiers in cellular and infection microbiology 4, 35

18. Collins, M. D., Falsen, E., Lemozy, J., Åkervall, E., Sjöden, B., and Lawson, P. A. (1997) Phenotypic and phylogenetic characterization of some Globicatella-like organisms from human sources: description of Facklamia hominis gen. nov., sp. nov. Int J Syst Bacteriol 47, 880-882

19. Collins, M. D., Lawson, P. A., Monasterio, R., Falsen, E., Sjöden, B., and Facklam, R. R. (1998) Facklamia ignava sp. nov., isolated from human clinical specimens. J Clin Microbiol 36, 2146-2148

20. Rahmati, E., Martin, V., Wong, D., Sattler, F., Petterson, J., Ward, P., Butler-Wu, S. M., and She, R. C. (2017) Facklamia Species as an Underrecognized Pathogen. Open Forum Infect Dis 4, ofw272

21. Mathews, C. K. (2016) The Most Interesting Enzyme in the World. Structure 24, 843-844

22. Jonna, V. R., Crona, M., Rofougaran, R., Lundin, D., Johansson, S., Brännström, K., Sjöberg, B. M., and Hofer, A. (2015) Diversity in overall activity regulation of ribonucleotide reductase. J Biol Chem 290, 17339-17348

23. Gaballa, A., Newton, G. L., Antelmann, H., Parsonage, D., Upton, H., Rawat, M., Claiborne, A., Fahey, R. C., and Helmann, J. D. (2010) Biosynthesis and functions of bacillithiol, a major low-molecular-weight thiol in Bacilli. Proc Natl Acad Sci U S A 107, 6482-6486

24. Fahey, R. C. (2013) Glutathione analogs in prokaryotes. Biochim Biophys Acta 1830, 3182-3198

25. Holmgren, A. (1976) Hydrogen donor system for Escherichia coli ribonucleosidediphosphate reductase dependent upon glutathione. Proc Natl Acad Sci U S A 73, 22752279

26. Lillig, C. H., Berndt, C., and Holmgren, A. (2008) Glutaredoxin systems. Biochim Biophys Acta 1780, 1304-1317

27. Zahedi Avval, F., and Holmgren, A. (2009) Molecular mechanisms of thioredoxin and glutaredoxin as hydrogen donors for Mammalian s phase ribonucleotide reductase. $J$ Biol Chem 284, 8233-8240

28. Bochner, B. R., and Ames, B. N. (1982) Complete analysis of cellular nucleotides by two-dimensional thin layer chromatography. J Biol Chem 257, 9759-9769

29. Buckstein, M. H., He, J., and Rubin, H. (2008) Characterization of nucleotide pools as a function of physiological state in Escherichia coli. J Bacteriol 190, 718-726

30. Cotruvo, J. A., Jr., Stich, T. A., Britt, R. D., and Stubbe, J. (2013) Mechanism of assembly of the dimanganese-tyrosyl radical cofactor of class $\mathrm{lb}$ ribonucleotide reductase: enzymatic generation of superoxide is required for tyrosine oxidation via a $\mathrm{Mn}(\mathrm{III}) \mathrm{Mn}(\mathrm{IV})$ intermediate. J Am Chem Soc 135, 4027-4039

31. Zheng, M., Khangulov, S. V., Dismukes, G. C., and Barynin, V. V. (1994) Electronic structure of dimanganese(II,III) and dimanganese(III,IV) complexes and dimanganese 
Glutaredoxin and ATP-cone fusions to ribonucleotide reductase

catalase enzyme - a general EPR spectral simulation approach. Inorg Chem 33, 382387

32. Berglund, O. (1975) Ribonucleoside diphosphate reductase induced by bacteriophage T4. III. Isolation and characterization of proteins B1 and B2. J Biol Chem 250, 74507455

33. Holmgren, A. (1989) Thioredoxin and glutaredoxin systems. J Biol Chem 264, 1396313966

34. Lillig, C. H., and Berndt, C. (2013) Glutaredoxins in thiol/disulfide exchange. Antioxid Redox Signal 18, 1654-1665

35. Mashamaite, L. N., Rohwer, J. M., and Pillay, C. S. (2015) The glutaredoxin mono- and di-thiol mechanisms for deglutathionylation are functionally equivalent: implications for redox systems biology. Biosci Rep 35

36. Begas, P., Staudacher, V., and Deponte, M. (2015) Systematic re-evaluation of the bis(2-hydroxyethyl)disulfide (HEDS) assay reveals an alternative mechanism and activity of glutaredoxins. Chem Sci 6, 3788-3796

37. Ukuwela, A. A., Bush, A. I., Wedd, A. G., and Xiao, Z. (2018) Glutaredoxins employ parallel monothiol-dithiol mechanisms to catalyze thiol-disulfide exchanges with protein disulfides. Chem Sci 9, 1173-1183

38. Haft, D. H., DiCuccio, M., Badretdin, A., Brover, V., Chetvernin, V., O'Neill, K., Li, W., Chitsaz, F., Derbyshire, M. K., Gonzales, N. R., Gwadz, M., Lu, F., Marchler, G. H., Song, J. S., Thanki, N., Yamashita, R. A., Zheng, C., Thibaud-Nissen, F., Geer, L. Y., Marchler-Bauer, A., and Pruitt, K. D. (2018) RefSeq: an update on prokaryotic genome annotation and curation. Nucleic Acids Res 46, D851-D860

39. Finn, R. D., Coggill, P., Eberhardt, R. Y., Eddy, S. R., Mistry, J., Mitchell, A. L., Potter, S. C., Punta, M., Qureshi, M., Sangrador-Vegas, A., Salazar, G. A., Tate, J., and Bateman, A. (2016) The Pfam protein families database: towards a more sustainable future. Nucleic Acids Res 44, D279-285

40. Eddy, S. R. (2011) Accelerated profile HMM searches. PLoS Comput Biol 7, e1002195

41. Holmgren, A., and Åslund, F. (1995) Glutaredoxin. Methods Enzymol 252, 283-292

42. Vlamis-Gardikas, A., Åslund, F., Spyrou, G., Bergman, T., and Holmgren, A. (1997) Cloning, overexpression, and characterization of glutaredoxin 2, an atypical glutaredoxin from Escherichia coli. J Biol Chem 272, 11236-11243

43. Kaufman, S. L., Skogen, J. W., Dorman, F. D., Zarrin, F., and Lewis, K. C. (1996) Macromolecule analysis based on electrophoretic mobility in air: globular proteins. Anal Chem 68, 1895-1904

44. Rofougaran, R., Crona, M., Vodnala, M., Sjöberg, B.-M., and Hofer, A. (2008) Oligomerization status directs overall activity regulation of the Escherichia coli class la ribonucleotide reductase. J Biol Chem 283, 35310-35318 